\title{
Enjoy!: The (phraseological) culture of having fun ${ }^{1}$
}

\author{
Monika Bednarek and Wolfram Bublitz
}

\section{Introduction}

Since culture, like numerous other aspects of reality, is not given but perpetually and actively construed through language, it reveals itself in language. In the attempt to understand the culture of a society, one wellestablished approach is to focus on the vocabulary of its language with its dual function of reflecting and (due to its conceptualizing and hypostatizing power) also defining the cultural concepts of a society. Both functions are crucial in the establishment and, through perpetual adjustment and alignment, reinforcement of the system of ideological beliefs and values, which constitutes the society's cultural identity. In this paper, we focus on the cultural concept of (having) fun by investigating the usage of the related cultural keyword enjoy in corpora of US-American and British English. Of course, single words only reveal their cultural significance when seen not in isolation but as part of a lexico-semantic network of words. Rather than focusing on enjoy as a single word, we therefore focus on its textual environment in order to investigate its distributional patterns. ${ }^{2}$ This procedure can tell us whether or not lexical expressions with enjoy serve as a kind of key to specific aspects of a fun-related ideology in US-American and British cultures.

We believe that to adopt such an extra-cultural position is generally a promising approach to our understanding of how intra-cultural patterns are encoded. The premise behind this approach is, of course, that the relevant social norms and thought patterns are culture-specific rather than universally shared (cf. Wierzbicka 1992). Anyone who is familiar with everyday life in the USA knows that the phrase Enjoy your meal/visit / trip! or the bare imperative Enjoy! are quite common, particularly in casual, informal communication, but also in some types of written texts (cf. below). For the outside observer, these forms appear to be somewhat unusual, not only from a grammatical but even more so from a pragmatic and socio-cultural point of view. Unlike other stative verbs such as have in Have a nice day / weekend / journey!, the verb enjoy allows the imperative even in those cases

\footnotetext{
Skandera, Paul (Editor). Topics in English Linguistics : Phraseology and Culture in English. Berlin, , DEU: Walter de Gruyter \& Co. KG Publishers, 2007. p 109.

http://site.ebrary.com/lib/utslibrary/Doc?id=10197234\&ppg=119

Copyright @ 2007 . Walter de Gruyter \& Co. KG Publishers. All rights reserved.

May not be reproduced in any form without permission from the publisher, except fair uses permitted under U.S. or applicable copyright law.
} 


\section{Monika Bednarek and Wolfram Bublitz}

(Enjoy!) in which it is used intransitively (but cf. *Have!). Other grammatical and distributional characteristics (including colligation and collocation) will be inspected in detail below.

From a pragmatic point of view, expressions with enjoy are generally regarded as a pronounced feature of polite interaction. This needs explaining in view of the fact that both their preferred form, the imperative, and their functional use mark them as directive speech acts. They are thus slightly questionable with respect to their true politeness value in terms of the potential face-threat they present. No matter how well-meant, telling someone to enjoy (something or themselves) can be understood as an intrusion into the recipient's right to self-determination. After all, an individual's well-being, happiness or enjoyment is a decidedly private matter. Expressions with Enjoy ...! differ from other directive conversational routines (also in imperative form) such as Help yourself? in that they are not a means of guiding a person's normal participation in social interaction. Instead, they direct the recipient to achieve a status of enjoyment or happiness, a condition that, as a rule, cannot be achieved willingly, as the outcome of a decision. Only if we assume that in cultures in which Enjoy ...! is routinely used, happiness, fun or, indeed, enjoyment are not regarded as private and optional matters but as public and obligatory assets, can we explain the directive function (as well as the imperative form) of enjoy. In a culture in which it is expected and even taken for granted that people wish to enjoy something or themselves, to be happy, to have fun, such concepts are regarded as essential and beneficial. Under this assumption, the directive enjoy ...! is easily explained not as a face-threatening request benefiting the speaker but, on the contrary, as a wish which benefits and thus actually promotes the recipient's positive face or sense of well-being. ${ }^{3}$

To corroborate this hypothesis, the obvious first step is to find out what exactly can be enjoyed or, rather, what people are usually told to enjoy. To this end, we will analyse not only the collocates of enjoy but also its semantic preference below.

Our investigation will focus on the immediate phraseological and distributional environment of enjoy both in US American and British English. The currently available general corpora with their broad spectrum of sources and genres can rightly be considered as "windows on our culture", as Mike McCarthy recently pointed out. ${ }^{4}$ Taking up his suggestion, we perused and juxtaposed corpora of British and American English in order to get access to the two societies' entrenched cultural patterns. Since it turned out that the subcorpora of spoken everyday casual conversation in both varieties (in

Skandera, Paul (Editor). Topics in English Linguistics : Phraseology and Culture in English. Berlin, , DEU: Walter de Gruyter \& Co. KG Publishers, 2007. p 110.

http://site.ebrary.com/lib/utslibrary/Doc?id=10197234\&ppg=120

Copyright (c) 2007. Walter de Gruyter \& Co. KG Publishers. All rights reserved.

May not be reproduced in any form without permission from the publisher, except fair uses permitted under U.S. or applicable copyright law. 
our data) are not large enough to provide a representative sample, it was necessary to turn to and thus to limit the analysis of enjoy to an examination of its usage in the 'ephemera' subcorpora of UK and US English, which are made up of a variety of persuasive texts (mostly related to public relations and advertisement, cf. below).

\section{Methodology}

Our data is taken from the British English (UK) and American English (US) subcorpora of the Bank of English. ${ }^{5}$ In order to identify most of the relevant usages of enjoy that we were interested in, we searched first for (a) Enjoy (in sentence initial position) in the base form following either punctuation and blank space or punctuation without blank space, (b) enjoy (in mid-sentence and clause initial position) in the base form following either punctuation and blank space or punctuation without blank space. In total, this search found 1,007 occurrences in the UK subcorpus and 420 occurrences in the US subcorpus (which is smaller than the UK corpus). We then went through all of the concordance lines manually, identifying those that were (most probably) used as imperatives, and excluding identical and quasi-identical lines. The final result were 693 occurrences in the UK subcorpus, compared to 338 occurrences in the US subcorpus.

However, enjoy was not distributed equally among the various subcorpora of both UK and US English. In fact, the only subcorpora that yielded enough occurrences in both varieties for a thorough linguistic analysis were the ephemera subcorpora, which, according to Ramesh Krishnamurthy (p.c.), are made up of a large variety of texts from pamphlets, catalogues, newsletters, leaflets, and brochures (mostly public relations material and advertisements) from different sources (e.g. banks, post offices, museums, tourist sites, community groups, etc.). ${ }^{6}$ As mentioned above, it was therefore necessary to limit the analysis of enjoy to an examination of its usage in these subcorpora. An additional search for or enjoy and and enjoy was then executed to yield more occurrences of enjoy used as a directive. The final result for the distribution of directive enjoy was as follows: 172 occurrences in the UK ephemera corpus vs. 306 occurrences in the US ephemera corpus. This result is surprising if we consider that the UK ephemera corpus (4,640,529 words) is in fact bigger than the US ephemera corpus $(3,506,272$ words). Some hypotheses concerning this finding will be advanced below.

Skandera, Paul (Editor). Topics in English Linguistics : Phraseology and Culture in English Berlin, , DEU: Walter de Gruyter \& Co. KG Publishers, 2007. p 111

http://site.ebrary.com/lib/utslibrary/Doc?id=10197234\&ppg=121

Copyright (c) 2007. Walter de Gruyter \& Co. KG Publishers. All rights reserved.

May not be reproduced in any form without permission from the publisher, except fair uses permitted under U.S. or applicable copyright law. 


\section{Monika Bednarek and Wolfram Bublitz}

In order to show how people use enjoy to routinely talk about a significant cultural aspect of their social life, and thus as a cultural keyword, we have to move from lexis to grammar, or rather, following Neo-Firthean linguistics, to an inter-level between lexis and grammar. Accordingly, we will focus on syntactically and semantically dependent co-occurrence patterns with enjoy, which have been described in different, though related ways, within lexico-grammatical theories (such as word grammar, construction grammar, pattern grammar etc.). Following them, we will now explore the colligation, semantic preference and collocation of enjoy in some detail.

\section{Colligation}

\subsection{Overview}

Colligation is defined by Sinclair as "the co-occurrence of grammatical phenomena" (2004: 142) and has similarities with the "patterns" identified by Hunston and Francis (2000) and the "schemas" analyzed by Stubbs (2001). A first glance shows that the different types of recurrent syntactic structures, i.e. the colligational patterns of enjoy are not distributed equally across the two subcorpora of UK and US English, as shown in table 1 below.

Without taking into account those structures which are too infrequent to be representative, it looks as if there is a preference in the UK corpus for the pattern enjoy + the $+\mathrm{NP}(41.9 \%)$, followed by enjoy + a/an + NP (20.9\%), enjoy + NP (20.3\%), and enjoy + unpremodified NP $(8.7 \%)$. In the US corpus, on the other hand, the most frequently used patterns are enjoy + NP (35.3\%), followed by enjoy + the + NP $(26.5 \%)$, enjoy + $a / a n+\mathrm{NP}(14 \%)$ and enjoy + unpremodified NP (13.7\%) (see figure 1 below).

The first conclusion to be drawn from this comparison is that UK persuasive texts and specifically advertisements clearly favour definite noun phrases (the $+\mathrm{NP}$ ), whereas in the US corpus premodified noun phrases without the definite article seem to be preferred. In order to explore the differences between the two corpora further, let us look at these colligational structures in more detail, focusing on their evaluative potential (which is, of course, the core function of the texts in the corpora: to evaluate the advertised products positively).

\footnotetext{
Skandera, Paul (Editor). Topics in English Linguistics : Phraseology and Culture in English. Berlin, , DEU: Walter de Gruyter \& Co. KG Publishers, 2007. p 112.

http://site.ebrary.com/lib/utslibrary/Doc?id=10197234\&ppg=122

Copyright @ 2007 . Walter de Gruyter \& Co. KG Publishers. All rights reserved.

May not be reproduced in any form without permission from the publisher, except fair uses permitted under U.S. or applicable copyright law.
} 
Table I. Colligational patterns

\begin{tabular}{|c|c|c|}
\hline Pattern & $\begin{array}{l}\text { UK } \\
\text { (172 occurrences) }\end{array}$ & $\begin{array}{l}\text { US } \\
\text { ( } 306 \text { occurrences) }\end{array}$ \\
\hline enjoy $+\emptyset$ & $5=2.9 \%$ & $12=3.9 \%$ \\
\hline enjoy + yourself/ves & $3=1.7 \%$ & $1=0.3 \%$ \\
\hline enjoy + (premod/det) numeral & $4=2.3 \%$ & $19=6.2 \%$ \\
\hline enjoy $+a^{\prime} / a n+$ noun phrase (NP) & $36=20.9 \%$ & $43=14 \%$ \\
\hline enjoy + the + noun phrase (NP) & $72=41.9 \%$ & $81=26.5 \%$ \\
\hline $\begin{array}{l}\text { enjoy + unpremodified noun phrase (NP) } \\
\text { consisting of a proper/common noun, ing- } \\
\text { form or pronoun }\end{array}$ & $15=8.7 \%$ & $42=13.7 \%$ \\
\hline Enjoy + noun phrase $(\mathrm{NP})^{8}$ & $35=20.3 \%$ & $108=35.3 \%$ \\
\hline all & $1=0.6 \%$ & $8=2.6 \%$ \\
\hline our & $3=1.7$ & $12=3.9 \%$ \\
\hline its & $2=1.2 \%$ & - \\
\hline his & - & $1=0.3 \%$ \\
\hline their & - & $6=2 \%$ \\
\hline your & $3=1.7 \%$ & $7=2.3 \%$ \\
\hline that / this / these & $4=2.3 \%$ & $6=2 \%$ \\
\hline Other (some, no, every) & $2=1.2 \%$ & $4=\%$ \\
\hline adjective as premodifier & $15=8.7 \%$ & $49=16 \%$ \\
\hline noun as premodifier & $2=1.2 \%$ & $13=4.2 \%$ \\
\hline$s$-genitive as premodifier & $3=1.7 \%$ & $2=0.6 \%$ \\
\hline and enjoy & $87=50.6 \%$ & $82=26.8 \%$ \\
\hline or enjoy & $10=5.8 \%$ & $4=1.3 \%$ \\
\hline Other & $2=1.2 \%$ & - \\
\hline
\end{tabular}

Skandera, Paul (Editor). Topics in English Linguistics : Phraseology and Culture in English. Berlin, , DEU: Walter de Gruyter \& Co. KG Publishers, 2007. p 113.

http://site ebrary.com/lib/utslibrary/Doc?id=10197234\&ppg=123

Copyright @ $\odot$ 2007. Walter de Gruyter \& Co. KG Publishers. All rights reserved.

May not be reproduced in any form without permission from the publisher, except fair uses permitted under U.S. or applicable copyright law. 


\section{Monika Bednarek and Wolfram Bublitz}

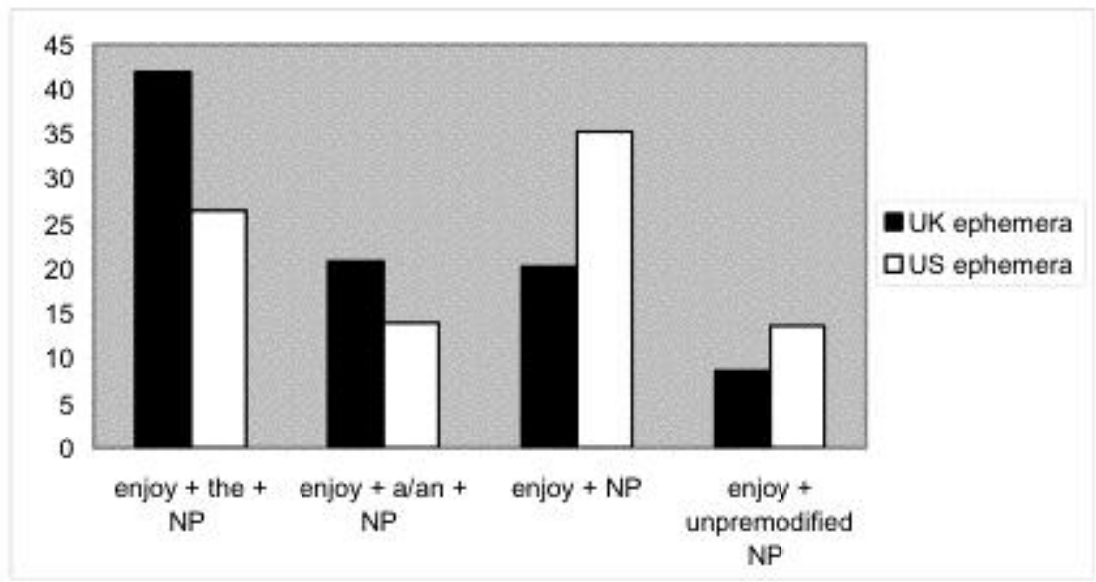

Figure 1. Frequent colligational patterns in the $\mathrm{AE}$ and $\mathrm{BE}$ ephemera subcorpora

\subsection{Enjoy the $+\mathrm{NP}$}

In the UK subcorpus there are 72 occurrences of the pattern enjoy + the $+\mathrm{NP}$. Of these, $56.9 \%$ (41 occurrences) are explicitly evaluative, using either contextually evaluative adjective + noun combinations (where either the adjective or noun or both are contextually evaluative) or the evaluative pattern the $+($ adj $)+$ evaluative noun + of $(21$ occurrences $)$. Here are some examples:

estate to industrial city. Enjoy the colourful brilliance of
italise those weary parts! Enjoy the natural beauty of this area and
o include this wonderland. Enjoy the freedom of this kind of
for more than 3,750 miles. Enjoy the splendour of the Forbidden City
esh with its edible seeds. Enjoy the delicate flavour sliced into
on, you take to the skies! Enjoy the magical scenery as you fly
lax on the large sun deck, enjoy the golden scenery drifting by, and
an Thaw in Home to Roost, enjoy the gentle humour of David Jason in
and and spectacular girls. Enjoy the electric atmosphere of a

The occurrences that are not as explicitly and clearly evaluative $(43.1 \%)$ in systemic-functional terms either name the (object of a mental process or) "phenomenon" (Halliday 1994: 117) to enjoy, or pick out a certain aspect of it $($ the + noun $+o f)$. Compare: 


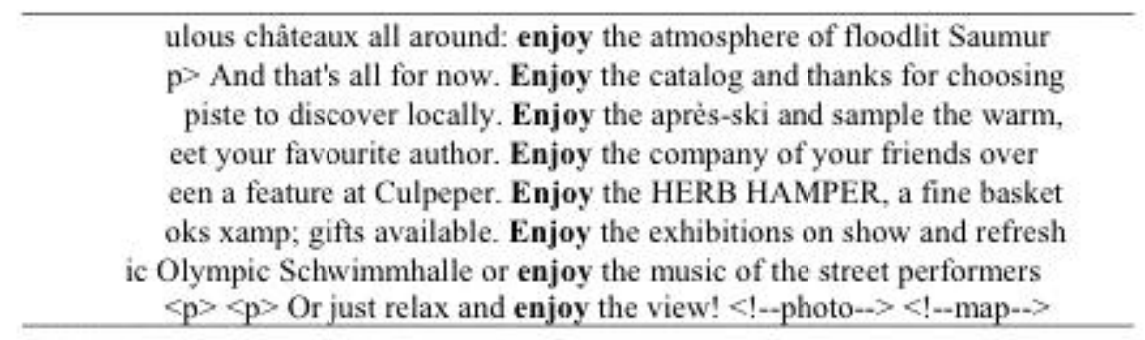

In the US subcorpus, the distribution is very similar: $55.5 \%$ of the occurrences of this pattern are explicitly (contextually) evaluative, compared to $44.4 \%$ of instances that are not. However, the evaluative pattern (the + evaluative noun $+o f$ ), that is quite frequent in the UK corpus (representing $29.1 \%$ of all occurrences within this colligational pattern), is in fact rather infrequent in the US corpus (12 occurrences, or $14.8 \%$, e.g. the convenience of, the delights of, the ease of, the enchantment of). There are, however, 33 occurrences of contextually evaluative adjective + noun combinations, for instance:

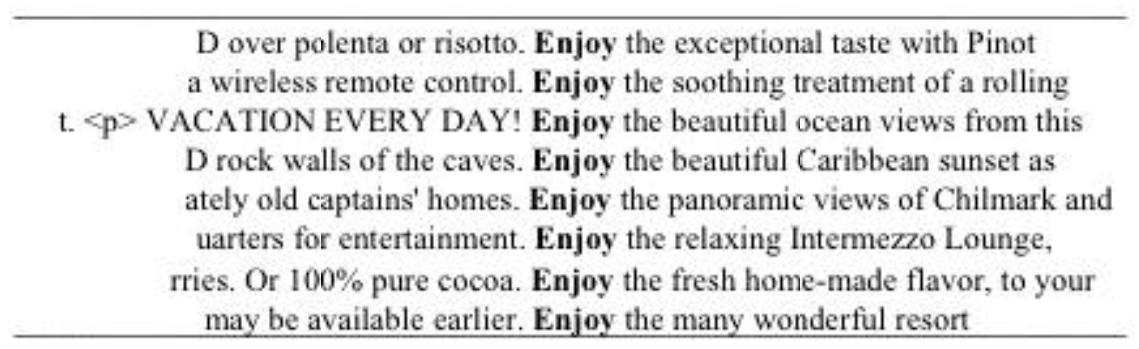

Thus, it seems as if evaluation by means of the evaluative noun + of pattern is more popular in the UK corpus than in the US corpus. In other words, in the British English ephemera corpus evaluation is preferably expressed through the head of a definite noun phrase (the beauty of the mountains), rather than through the premodifier(s) of a definite noun phrase (the beautiful mountains). The effect of this is difficult to pinpoint. When expressed as head, the evaluation seems to shift its focus slightly away from the target object (mountains) to the evaluative noun (beauty). This has to do with the well-known concept-defining function of lexemes together with the specific cognitive function of nouns to reify and hypostatize highly complex fragments of reality as gestalt-like entrenched concepts. The result of reification and hypostatization is that a category is called into existence not only

Skandera, Paul (Editor). Topics in English Linguistics : Phraseology and Culture in English. Berlin, , DEU: Walter de Gruyter \& Co. KG Publishers, 2007. p 115.

http://site.ebrary.com/lib/utslibrary/Doc?id=10197234\&ppg=125

Copyright (c) 2007. Walter de Gruyter \& Co. KG Publishers. All rights reserved.

May not be reproduced in any form without permission from the publisher, except fair uses permitted under U.S. or applicable copyright law. 


\section{Monika Bednarek and Wolfram Bublitz}

as an autonomous and neatly-bounded entity but also as a set of essential properties. Premodification with an adjective, on the other hand, is less stable and much more transitory. Thus, preferring the noun beauty as the head of the noun phrase the beauty of the mountains to the premodifying adjective beautiful in the beautiful mountains is a subtle but effective way of foregrounding the existence of the concept beauty (thereby weakening the relation to its scope, the mountains). The positive evaluation of mountains seems to be moderately 'stronger' when carried by a premodifier. The following analyses of the other patterns with enjoy will reveal that the tendency to prefer 'stronger' forms of evaluation is, in fact, a characteristic trait of US persuasive texts.

\subsection{Enjoy $+\mathrm{NP}$}

Examining the next pattern (enjoy + premodifier etc. + noun) in more detail we see that, although this pattern is more frequent in the US corpus, the difference in terms of the evaluation expressed by this pattern is minimal:

Table 2. Enjoy + premodifer etc. $+\mathrm{NP}$

\begin{tabular}{|c|c|c|}
\hline evaluation & $\begin{array}{l}\operatorname{UK}(35) \\
19=54.3 \%\end{array}$ & $\begin{array}{l}\text { US }(108) \\
64=59.3 \%\end{array}$ \\
\hline \multirow{3}{*}{$\begin{array}{l}\text { mention of phenomenon } \\
\text { (no explicit evaluation) }\end{array}$} & $\begin{array}{l}\text { e.g. } \\
\text { cheaper, higher, total, } \\
\text { stunning, splendid, su- } \\
\text { perb, benefits }\end{array}$ & $\begin{array}{l}\text { e.g. } \\
\text { greater, superior, full, } \\
\text { splendid, breathtaking, } \\
\text { spectacular, benefits, } \\
\text { pleasures, beauty }\end{array}$ \\
\hline & $16=45.7 \%$ & $44=40.7 \%$ \\
\hline & $\begin{array}{l}\text { e.g. } \\
\text { traditional and contempo- } \\
\text { rary music, this brochure, } \\
\text { that meal, its scenery }\end{array}$ & $\begin{array}{l}\text { e.g. } \\
\text { Members-only discounts, } \\
\text { emergency cash, German } \\
\text { music and dancing, } \\
\text { nightly entertainment }\end{array}$ \\
\hline
\end{tabular}

In both subcorpora this pattern is used predominantly to evaluate the phenomena to be enjoyed with the help of comparative, intensifying or evaluative adjectives (rather than nouns), in contrast to simply mentioning the phenomena. This tendency is even higher in the US subcorpus.

Skandera, Paul (Editor). Topics in English Linguistics : Phraseology and Culture in English. Berlin, , DEU: Walter de Gruyter \& Co. KG Publishers, 2007. p 116

http://site.ebrary.com/lib/utslibrary/Doc?id=10197234\&ppg=126

Copyright $\odot$ 2007. Walter de Gruyter \& Co. KG Publishers. All rights reserved.

May not be reproduced in any form without permission from the publisher, except fair uses permitted under U.S. or applicable copyright law. 


\subsection{Enjoy $+a / a n+\mathrm{NP}$}

As to the pattern involving indefinite noun phrases, we found that in the UK subcorpus (36 occurrences) a majority of such instances simply mention the phenomenon to enjoy (20 occurrences or $55.5 \%$ ), in contrast to explicitly evaluative patterns ( 16 occurrences or $44.4 \%$ ). In the US subcorpus ( 43 occurrences), on the other hand, mention of the phenomenon is only a little more frequent ( 23 occurrences or $53.5 \%$ ) than evaluative patterns ( 20 occurrences or $46.5 \%$ ). Here are some examples:

explicitly evaluative patterns

itional Italian ice cream, enjoy a mouth watering

I and apply to your teeth. Enjoy a pleasant, tingling

$s$ that look down on Veosc. Enjoy a leisurely drink of

1 anchor in a remote cove; enjoy a refreshing swim

exico. Drive to Chihuahua. Enjoy a festive welcome $y$ kinds of fruit and nuts. Enjoy a lovely walk of of

mention of phenomenon

TASTED, NEVER FORGOTTEN. Enjoy a plate of mou immense, clear blue lakes. Enjoy a picnic in a flo rchase. $\langle p\rangle$ Come along and enjoy a chat with fric $t^{\prime \prime}$ hot and cold salad bar. Enjoy a lunch buffet Radisson Hotels Worldwide. Enjoy a weekend for ure. In the early evening, enjoy a trishaw ride 


\section{Preface}

The proposition that there is a correlation between language and culture or culture-specific ways of thinking can be traced back to the views of Herder and von Humboldt in the late 18th and early 19th centuries. It was most explicitly formulated, however, by the German-American linguist and anthropologist Edward Sapir in various publications from 1929 onward (republished posthumously in 1949 under the title Selected writings of Edward Sapir in language, culture and personality), and in the writings of his pupil Benjamin Lee Whorf (republished posthumously in 1956 as Language, thought, and reality: Selected writings of Benjamin Lee Whorf). The Sapir-Whorf hypothesis, as it came to be called, expresses the notion that different languages lead their speakers to different conceptualizations of the same extralinguistic reality, which seems to be most evident in the way that reality is segmented by the lexicon.

Even though few linguists would fully agree with a strict reading of the Sapir-Whorf hypothesis today, it is generally accepted that a language, especially its lexicon, influences its speakers' cultural patterns of thought and perception in various ways, for example through a culture-specific segmentation of the extralinguistic reality, the frequency of occurrence of particular lexical items, or the existence of keywords or key word combinations revealing core cultural values. Nevertheless, the exact workings of the link between language and culture are still poorly understood. The few specific theoretical frameworks that do exist are often felt to be inadequate, and the research methodology is only insufficiently developed (it is telling, in this context, that the methods employed by Whorf in particular seem to have had serious shortcomings).

The aim of this volume, then, is to explore the cultural dimension of a wide range of preconstructed or semi-preconstructed word combinations in English. These include highly opaque multiword units of the kick-thebucket type, collocations, irreversible binominals, phrasal verbs, compounds, metaphorical expressions, similes, proverbs, familiar quotations, catchphrases, clichés, slogans, expletives, and discourse markers such as politeness formulae - all of which have been subsumed under phraseology, or under idiom in the Anglo-American linguistic tradition. The volume is divided into four sections, focusing on particular lexemes (e.g. enjoy and its

\footnotetext{
Skandera, Paul (Editor). Topics in English Linguistics : Phraseology and Culture in English. Berlin, , DEU: Walter de Gruyter \& Co. KG Publishers, 2007. p v.

http://site.ebrary.com/lib/utslibrary/Doc?id=10197234\&ppg=5

Copyright (c) 2007. Walter de Gruyter \& Co. KG Publishers. All rights reserved.

May not be reproduced in any form without permission from the publisher, except fair uses permitted under U.S. or applicable copyright law.
} 


\section{vi Preface}

collocates), types of word combinations (e.g. proverbs and similes), userelated varieties (such as the language of tourism or answering-machine messages), and user-related varieties (such as Aboriginal English or African English). The assignment of the papers to these sections is, of course, not always clear-cut: Many of the papers address issues pertaining to more than one section, and the dividing lines between the sections are therefore permeable, rather than rigid. The sections are preceded by a prologue, tracing the developments in the study of formulaic language, and followed by an epilogue, which draws together the threads laid out in the various papers, and ends with a résumé of the research questions raised in the prologue. The epilogue also draws attention to good academic practice in a way that, it is hoped, will encourage other researchers to conceptualize their projects carefully, both in terms of procedures and assumptions, and also in terms of the potential theoretical import of their work.

There are a number of important works, published in the past fifteen years, that explore the relation between language and culture in general, but the study of the relation between English phraseology and culture in particular has been largely neglected. This volume is the first book-length publication devoted entirely to this topic. It should be of interest to all those interested in phraseology (or idiomatology) and variational linguistics, and to those interested in the interface between language and culture, which is a particular concern in cognitive linguistics and anthropological linguistics.

I would like to thank Penny Lee for reading an earlier draft of the typescript and making valuable comments toward its improvement. I am also grateful to Karin Stettler for competently preparing the typescript and for her endless patience over the years, and to Susanne Jantos for doing the hard work of compiling the index.

Paul Skandera

Innsbruck, Austria

October 2006

\footnotetext{
Skandera, Paul (Editor). Topics in English Linguistics : Phraseology and Culture in English. Berlin, , DEU: Walter de Gruyter \& Co. KG Publishers, 2007. p vi.

http://site.ebrary.com/lib/utslibrary/Doc?id=10197234\&ppg=6

Copyright $\odot$ 2007. Walter de Gruyter \& Co. KG Publishers. All rights reserved.

May not be reproduced in any form without permission from the publisher, except fair uses permitted under U.S. or applicable copyright law.
} 


\section{Contents}

Preface

Paul Skandera

\section{Prologue}

Developments in the study of formulaic language since 1970:

A personal view

Andrew Pawley

\section{Focus on particular lexemes}

Reasonably well: Natural Semantic Metalanguage as a tool for the study of phrascology and its cultural underpinnings

Anna Wierzbicka

Australian perceptions of the weekend: Evidence from collocations and elsewhere

Bert Peeters

Enjoy!: The (phraseological) culture of having fun

Monika Bednarek and Wolfram Bublitz

Hot, heiß, and gorjachij: A case study of collocations in English, German, and Russian

Doris Schönefeld

\section{Focus on types of idioms}

Collections of proverbs and proverb dictionaries: Some historical observations on what's in them and what's not (with a note on current "gendered" proverbs)

Charles Clay Doyle

Skandera, Paul (Editor). Topics in English Linguistics : Phraseology and Culture in English.

Berlin, , DEU: Walter de Gruyter \& Co. KG Publishers, 2007. p vii.

http://site.ebrary.com/lib/utslibrary/Doc?id=10197234\&ppg=7

Copyright @ 2007. Walter de Gruyter \& Co. KG Publishers. All rights reserved.

May not be reproduced in any form without permission from the publisher, except fair uses permitted under U.S. or applicable copyright law. 